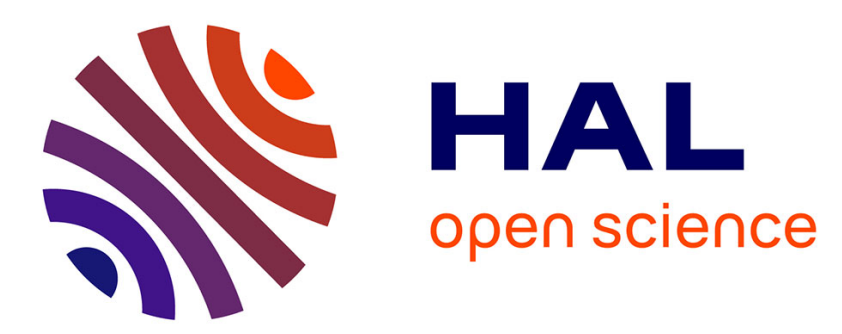

\title{
Towards a model for electric vehicle noise emission in the European prediction method CNOSSOS-EU
}

Marie Agnès Pallas, Michel Berengier, Roger Chatagnon, Martin Czuka, Marco Conter, Matthew Muirhead

\section{- To cite this version:}

Marie Agnès Pallas, Michel Berengier, Roger Chatagnon, Martin Czuka, Marco Conter, et al.. Towards a model for electric vehicle noise emission in the European prediction method CNOSSOS-EU. Applied Acoustics, 2016, 113, pp.89-101. 10.1016/j.apacoust.2016.06.012 . hal-01355872

\section{HAL Id: hal-01355872 \\ https://hal.science/hal-01355872}

Submitted on 24 Aug 2016

HAL is a multi-disciplinary open access archive for the deposit and dissemination of scientific research documents, whether they are published or not. The documents may come from teaching and research institutions in France or abroad, or from public or private research centers.
L'archive ouverte pluridisciplinaire HAL, est destinée au dépôt et à la diffusion de documents scientifiques de niveau recherche, publiés ou non, émanant des établissements d'enseignement et de recherche français ou étrangers, des laboratoires publics ou privés. 


\title{
Towards a model for electric vehicle noise emission in the European prediction method CNOSSOS-EU
}

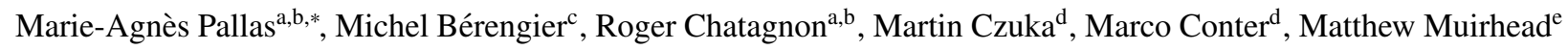 \\ ${ }^{a}$ Université de Lyon, CeLyA, F-69000, Lyon, France \\ ${ }^{b}$ IFSTTAR, AME, LAE, F-69500 Bron, France \\ ${ }^{c}$ LUNAM Université, IFSTTAR, AME, LAE, F-44340 Bouguenais, France \\ ${ }^{d}$ AIT Austrian Institute of Technology GmbH, Vienna, Austria \\ ${ }^{e}$ TRL, Crowthorne House, Nine Mile Ride, RG40 3GA Wokingham, UK
}

\begin{abstract}
The CNOSSOS-EU method is recommended in Europe for environmental noise prediction. In regards to road traffic, it includes vehicle noise emission models implicitly referring to internal combustion vehicles. The development of electrically driven vehicles calls for the future consideration of these vehicles in prediction models. On the basis of experimental data, the study reported in this paper proposes a noise emission model for extending CNOSSOSEU to light electric vehicles. Correction terms to be applied to the propulsion noise component are determined. Investigations on a sample of tyres with good rolling resistance performance, which is a main tyre selection criterion on these vehicles, indicated that no correction is required for the rolling noise component. Differences between the noise emission from conventional vehicles and electric vehicles are discussed for several road surfaces. Owing to the limited vehicle sample as well as transitional statements, this new model for electric vehicles running at constant speed over $20 \mathrm{~km} / \mathrm{h}$ should be considered as a first step towards the definition of this vehicle technology in CNOSSOS-EU.
\end{abstract}

Keywords: electric vehicle, vehicle noise, propulsion noise, rolling noise, noise prediction, CNOSSOS-EU, tyre label

\section{Introduction}

In European countries, road traffic noise is indicated by citizens as one of the main nuisances. It also proves to be the major source of population noise exposure both inside and outside European urban areas [1]. To add to the discomfort and annoyance in common life situations, its harmful impacts on long-term health are now widely 5 acknowledged [2, 3]. The European Directive 2002/49/EC has been constructed as a policy instrument to assess and manage environmental noise [4]. Among several objectives, it aims at developing prevention and reduction of environmental noise, in particular regarding road vehicles and infrastructure. Further to the legislation limiting the noise emission of motor vehicles and tyres [5, 6], the development of vehicles using electric traction - either purely electric vehicles (EVs) or hybrid electric vehicles (HEVs), the latter including range-extender electric vehicles potentially provides an additional opportunity for a reduction in environmental noise from vehicles. First designed and promoted for their quality in terms of air pollution control within cities, their use is definitely increasing on European road networks too. This expansion is supported by the electric range improvement (battery performance and durability) and the increasing offer of recharging stations on road networks. In parallel, financial support for green vehicle purchase granted by several State members and the commercial offers proposed by some manufacturers encourage the electric fleet development, even though its share of the overall vehicle fleet still remains low [7].

\footnotetext{
${ }^{*}$ Corresponding author

Email address: marie-agnes.pallas@ifsttar.fr (Marie-Agnès Pallas)

URL: www.lae.ifsttar.fr (Marie-Agnès Pallas)
} 
Noise-related research on these vehicles has been mainly focused on urban situations, generally regarding safety aspects related to their low-noise emission and the ensuing awkward audio detectability in usual urban traffic background noise, less frequently considering environmental noise impact. As an example to this latter design the European project City Hush considered "acoustically green road vehicles"and proposed noise criteria for the access of vehicles in quiet zones in cities [8]. For fairly detailed literature reviews, the reader is referred to the references [9] and [10]. To date, little attention has been devoted to the noise impact of electrically powered vehicles on national roads from a physical and quantitative point of view. Standardized environmental noise prediction relies on assessment methods considering exclusively noise emission data from internal combustion engine (ICE) vehicles. However, the harmonized European method CNOSSOS-EU (Common NOise aSSessment methOdS) offers, in advance, an open vehicle category, available for possible future needs such as new vehicle technologies [11]. Also, some noise emission data based on one specific range extended electric vehicle was proposed for completing the American standardized assessment method (REMEL) in ref. [12].

The present paper proposes noise emission data for considering light electric vehicles in the harmonized European prediction method CNOSSOS-EU, which describes the recommended framework for strategic noise mapping under

30 the Environmental Noise Directive (2002/49/EC). This proposal results from experimental data measured on a sample of vehicles. Considering the fairly limited vehicle dataset involved in this study, this proposal is a first step towards taking these new vehicles into consideration in CNOSSOS-EU. The study was conducted within the framework of the project FOREVER (Future Operational Impacts of Electric Vehicles on national European Roads), aiming more widely at assessing the acoustical impact of these new vehicle propulsion technologies, according to projections of 35 their medium-term deployment in the vehicle fleet. The European regulation No 540/2014 imposes on manufacturers of electric and hybrid vehicles in the near future to equip their vehicles with Acoustic Vehicle Alerting Systems (AVAS) to improve the auditory detectability by other vulnerable road users. Since the presence of such systems on these vehicles was still marginal at the time of the study, they have not been considered in the vehicle noise emission.

The standard CNOSSOS-EU method, as stated in section 2, sets ICE vehicle noise emission through two com40 ponents: a propulsion noise component and a rolling noise component, both described in octave bands for specific reference conditions and various vehicle categories. Correction terms are available if conditions differ from the reference ones. Section 3 specifically concerns electric vehicles. It derives the corresponding propulsion noise component from measurements performed on a sample of electric vehicles by setting new correction terms to be applied to the original ICE propulsion data (subsection 3.1). The rolling noise component is inferred from a sample of environmentally-friendly tyres — including tyres recommended for electric vehicles — measured on one electric vehicle (subsection 3.2). Incidentally, the rolling noise levels and the corresponding tyre ranking are compared with the European labels set up to inform the consumer on their environmental performance. Finally, the complete EV noise emission model is compared with the standard ICE model (section 4). Lastly, some conclusions will be drawn on the effective impact of these new vehicles, considering also various road surface types.

\section{2. Vehicle noise emission in the European model CNOSSOS-EU}

The Common NOise aSSessment methOdS (CNOSSOS-EU) were developed with the main objective "to build a set of consistent tools capable of providing comparable results from the strategic noise mapping carried out by the EU member states to fulfil their obligation under the European Directive on the Assessment and Management of Environmental Noise (2002/49/EC)" [11]. They include specifications for road traffic, railway traffic, aircraft and 5 industrial noise. Only the road traffic part is concerned and reported here. The road traffic noise prediction relies on the description of the source emission and on the calculation of the sound propagation. At the basis of the noise source emission is the specification of a single moving equivalent vehicle. Since 2012, some amendments have been proposed. They have been introduced in the description below, according to the updated final version [13].

The CNOSSOS-EU model is based on a combination of four categories of vehicle, according to their size and number of axles. Light vehicles correspond to category 1 . This category is of particular interest in the present study and concerns "passenger cars, delivery vans less than 3.5 tons, Sport Utility Vehicles (SUVs), Multi-Purpose Vehicles (MPVs) including trailers and caravans". Medium-heavy and heavy vehicles are respectively in categories 2 and 3. Category 4 concerns powered two-wheelers. A fifth category, named 'open category', has been left available for future needs. 


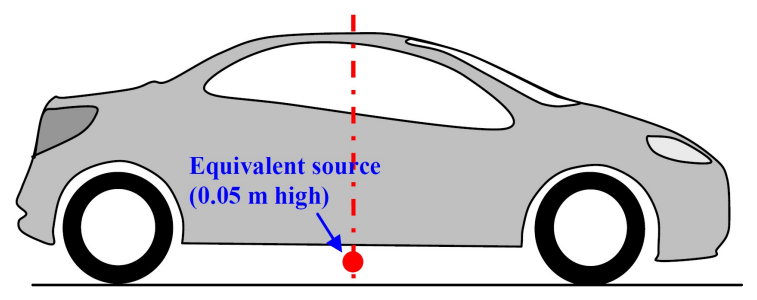

Figure 1: Location of the equivalent point source on light vehicles (from [11])

In each category, the individual vehicle is represented by one single point source placed $0.05 \mathrm{~m}$ over the road surface (Figure 1). The noise contribution of a vehicle is described by the sound power emitted in $\mathrm{dB}$ in semi-free field conditions. Implicitly, the model refers to internal combustion engine (ICE) vehicles. CNOSSOS-EU provides a similar noise emission model for all vehicles in categories 1 to 3 (light, medium and heavy vehicles), composed of a propulsion noise component and a rolling noise component, each one depending on the vehicle speed through two specific parameters A and B which are given in octave bands (from $63 \mathrm{~Hz}$ to $8000 \mathrm{~Hz}$ ) for each category. For category 4 , the rolling noise component is nonexistent since the propulsion noise is supposed to be dominating. The equations of the noise emission model are available at all speeds greater than $20 \mathrm{~km} / \mathrm{h}$. At speeds lower than $20 \mathrm{~km} / \mathrm{h}$, the sound power level in the model remains equal to the value at $20 \mathrm{~km} / \mathrm{h}$ [13]. In each category, correction coefficients can be applied to the model components if the conditions deviate from the reference conditions. These correction terms are either constant, speed dependent, or dependent on another parameter. The reference conditions include [11]:

- a constant vehicle speed,

- a flat and dry road,

- an air temperature of $20^{\circ} \mathrm{C}$,

- a virtual reference road surface consisting of an average of Dense Asphalt Concrete (DAC) 0/11 and Stone Mastic Asphalt (SMA) 0/11, between 2 and 7 years old,

- no studded tyres.

\subsection{Propulsion noise component}

The propulsion noise is defined as a linear function of the speed $v$. It includes the contributions from the driveline, i.e. engine, exhaust, gears, air intake, etc. The sound power level $L_{W P, i}$ is formulated by:

$$
L_{W P, i}(v)=A_{P, i}+B_{P, i}\left(\frac{v-v_{r e f}}{v_{r e f}}\right)+\Delta L_{W P, i}(v)
$$

where

- $A_{P, i}$ and $B_{P, i}$ are the propulsion noise coefficients given in the octave band $i$ (from $63 \mathrm{~Hz}$ to $8000 \mathrm{~Hz}$ ) for the reference speed $v=70 \mathrm{~km} / \mathrm{h}$. They are specific to each vehicle category.

- $\Delta L_{W P, i}(v)$ is a sum of correction coefficients for conditions deviating from the reference conditions, accounting respectively for the road surface type $\left(\Delta L_{W P, \text { road }, i}\right)$, the effect of acceleration near traffic lights or roundabouts $\left(\Delta L_{W P, a c c, i}\right)$, and the effect of road gradients $\left(\Delta L_{W P, g r a d, i}\right)$ :

$$
\Delta L_{W P, i}(v)=\Delta L_{W P, \text { road }, i_{i}}+\Delta L_{W P, a c c, i}+\Delta L_{W P, g r a d, i}(v)
$$




\subsection{Rolling noise component}

The rolling noise (including the aerodynamic noise) is defined as a logarithmic function of the speed $v$. The sound power level $L_{W R, i}$ is formulated by:

$$
L_{W R, i}(v)=A_{R, i}+B_{R, i} \log \left(\frac{v}{v_{r e f}}\right)+\Delta L_{W R, i(v)}
$$

where

- $A_{R, i}$ and $B_{R, i}$ are the rolling noise coefficients given in the octave band $i$ (from $63 \mathrm{~Hz}$ to $8000 \mathrm{~Hz}$ ) for the reference speed $v_{\text {ref }}=70 \mathrm{~km} / \mathrm{h}$. They are specific to each vehicle category.

- $\Delta L_{W R, i}(v)$ is a sum of correction factors taking into account respectively the road surface type $\left(\Delta L_{W R, \text { road,i }}\right)$, the proportion of vehicles with studded tyres $\left(\Delta L_{\text {studded, } i}\right)$, the effect of acceleration near traffic lights or roundabout $\left(\Delta L_{W R, a c c, i}\right)$, the effect of temperature $\tau\left(\Delta L_{W, t e m p}\right)$ :

$$
\Delta L_{W R, i}(v)=\Delta L_{W R, \text { road }, i}(v)+\Delta L_{\text {studded }, i}(v)+\Delta L_{W R, a c c, i}+\Delta L_{W, t e m p}(\tau)
$$

\subsection{Road surfaces}

Spectral correction factors may be applied to the vehicle noise emission model if the road surface type acoustically differs from the reference one. The propulsion noise component is affected in the case of porous surfaces only, so as to convey the absorption property of these surfaces. Spectral correction factors for the rolling noise component are recommended both for dense and porous surfaces. They follow the equations [11]:

$$
\begin{array}{rll}
\text { dense or porous surfaces } & : & \Delta L_{W R, \text { road }, i}(v)=\alpha_{i}+\beta \log \left(\frac{v}{v_{\text {ref }}}\right) \\
\text { porous surfaces only } & : & \Delta L_{W P, \text { road }, i}=\min \left\{\alpha_{i} ; 0\right\}
\end{array}
$$

where $\Delta L_{W R, \text { road }, i}$ and $\Delta L_{W P, \text { road }, i}$ are the correction terms of the rolling and the propulsion noise respectively. $\alpha_{i}$ is the spectral correction in $\mathrm{dB}$ in the octave band $i$ at the reference speed $v_{\text {ref }}$, and $\beta$ is the speed effect, both coefficient values being specific to each vehicle category. Equation 6 is only available for porous surfaces and can only express a propulsion noise reduction.

Correction coefficient values corresponding to fourteen road surfaces are provided in the amended version of CNOSSOS [13], with a speed range validity specific to each surface. In the following, in addition to the reference surface of the method, illustrations of the model will be provided for two other surfaces, selected as being representative of a common dense surface and a low noise pervious surface in several National Road Methods:

- SMA-NL8: Stone Mastic Asphalt with stones of maximum 8 mm, as a dense surface,

- Thin layer A: Thin layer low noise asphalt Type A, as a pervious surface.

In this paper, the noise prediction model is investigated by considering sound pressure levels at the standard position located at $7.5 \mathrm{~m}$ from the lane centre and at a height of $1.2 \mathrm{~m}$, the vehicle being represented in every respect as stated in CNOSSOS-EU either in the reference conditions or with either of the two other road surfaces selected above. Figure 2 represents the propulsion noise component, the rolling noise component and the total noise in each octave band from 125 to $4000 \mathrm{~Hz}$, whereas figure 3 shows the noise emitted by the vehicle and received at the track side in global levels. The porous absorption property is mainly noticeable in the octave bands from and above $1000 \mathrm{~Hz}$ and has equal effects on each noise component due to the CNOSSOS model principle for porous surfaces. Consequently it does not change the relative importance of the propulsion and the rolling noise. These three surfaces form the conditions retained for the ICE vehicle noise emission to be subsequently compared with the EVs emission. 

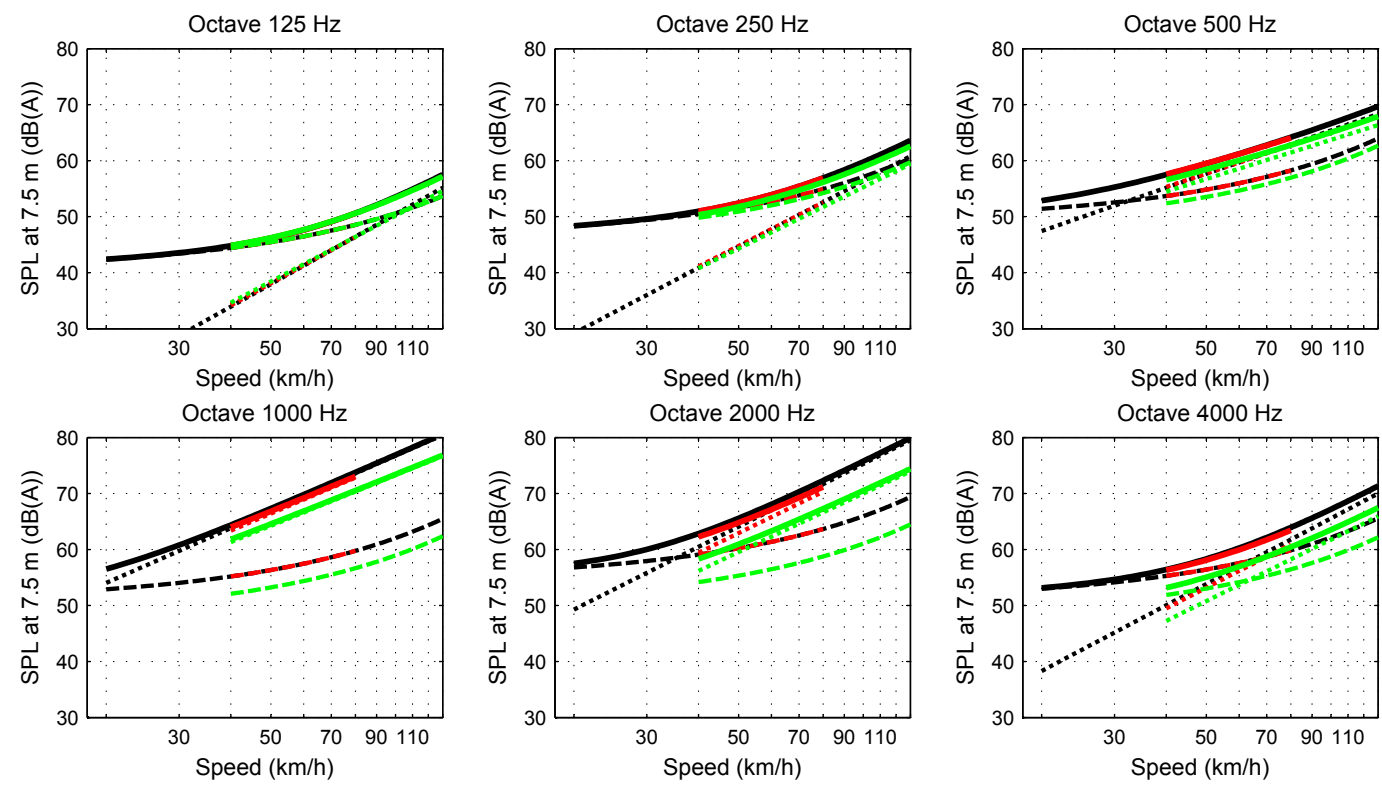

Figure 2: Sound Pressure Level in $\mathrm{dB}(\mathrm{A})$ per octave band at $7.5 \mathrm{~m}$ from the track centre associated with the conventional vehicle noise emission of CNOSSOS-EU, in the reference conditions (black), with the SMA-NL8 (red) and the Thin Layer A (green) road surfaces - propulsion noise component (--), rolling noise component $(\cdots)$, total noise (-)

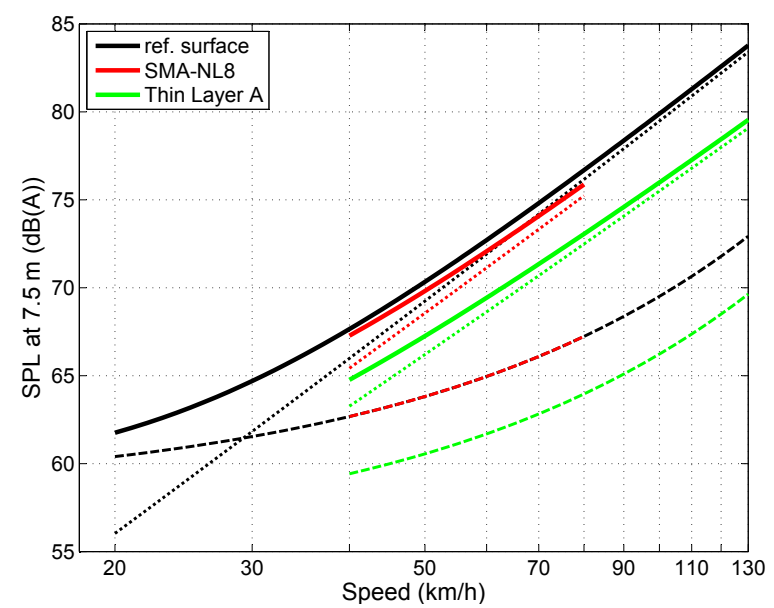

Figure 3: Global Sound Pressure Level in $\mathrm{dB}(\mathrm{A})$ at $7.5 \mathrm{~m}$ from the track centre associated with the conventional vehicle noise emission of CNOSSOS-EU, in the reference conditions (black), with the SMA-NL8 (red) and the Thin Layer A (green) road surfaces - propulsion noise component (--), rolling noise component $(\cdots)$, total noise $(-)$ 


\section{Noise emission from electric vehicles}

The approach followed to derive a model for electric vehicles in the CNOSSOS method results from two main experimental investigations conducted in parallel, for determining a propulsion noise component and a rolling noise component:

- propulsion noise component: the noise emission of a sample of electrically powered vehicles has been explored and compared with a sample of several ICE vehicles, both measured on one common test road,

- rolling noise component: the noise emission of a sample of different tyre types with the same size, fitted to one electric vehicle and selected as environmentally friendly, has been evaluated on one test road.

In itself, this process differs from the methodology originally used for defining CNOSSOS-EU, which relied on statistics based on a wide number of ICE vehicle measurements. As such, the present electric vehicle/tyre sample cannot be considered as statistically significant but constitutes a first step towards the definition of a validated model.

Electrically driven vehicles are well-known to be low-noise vehicles. Thus, it may be difficult to perform meaningful noise emission measurement in a common background noise environment, in particular in some frequency bands. Consequently, the analysis bandwidth considered as valid in this study ranges from the octave $125 \mathrm{~Hz}$ to the octave $4000 \mathrm{~Hz}$ and global levels refer to this frequency range.

\subsection{Propulsion noise emission of electric vehicles}

\subsubsection{Evidence for correcting EV propulsion noise component}

Noise emission data measured in similar conditions from a sample of eight different electrically powered vehicles have been gathered, involving both small and larger light vehicles. Five of them were tested on a DAC 0/10 road surface from low speeds up to $110 \mathrm{~km} / \mathrm{h}$ and three others on a SMA 0/14 surface up to $50 \mathrm{~km} / \mathrm{h}$. Both road surfaces are dense surfaces but with a different roughness. The acoustic quantity considered is the $L_{A F m a x}$ at vehicle cruise-by on a microphone located at a distance of $7.5 \mathrm{~m}$ from the track centre and at a height of $1.2 \mathrm{~m}$, in accordance with standard Controlled Pass-by (CPB) experimental conditions [14]. Global levels as well as levels in octave bands, from $125 \mathrm{~Hz}$ to $4000 \mathrm{~Hz}$, are considered. Noise levels increase mostly linearly with $\log ($ speed $)$, but the trend is generally not linear in the low frequency bands. Based on what is most appropriate, linear or quadratic regression curves are used for representing the noise increase with $\log ($ speed) (Figures 4 and 5). When comparing with the propulsion noise component of the CNOSSOS-EU model - which is independent of the road surface as far as dense surfaces are involved - and temporarily putting aside the rolling noise contribution, it turns out that in several octave bands and in global levels, the sole propulsion noise component clearly overestimates the total noise of the vehicle at low speed, bringing up the need for an adaptation of this component to EVs in the prediction model.

\subsubsection{Selection and description of the approach}

The proposal for a description of light electric vehicles in CNOSSOS can be considered in two ways, either by defining a new vehicle category (using the 'open category' opportunity offered in CNOSSOS-EU) or by recommending additional correction coefficients to the noise components available for category 1.

As a preliminary, some information concerning ICE vehicles should be mentioned. Most ICE vehicles are equipped with a gearbox offering discrete transmission ratios, so that engine speed and vehicle speed are linked together according to the selected gear, involving a two parameter (engine rpm and gear ratio) relationship to vehicle speed. Propulsion noise sources and rolling noise sources are often neighbouring due to the position of the engine in the proximity of an axle. Even though common source separation methods like beamforming may fail to clearly distinguish them through their positions at some frequencies, the consideration of the two parameter degrees of freedom of the driveline introduces a complementary noise separation ability [9].

Previous attempts for separating propulsion from rolling noise in the sound measures performed at electric vehicle pass-by have not been successful. In fact, electric vehicles have generally no gearbox. Thus, vehicle speed and engine speed, respectively leading rolling noise and propulsion noise components, are proportional and form a single degree of freedom. While the tyre-road contact area and the electric motor ${ }^{1}$ are very close noise sources, the above noise

\footnotetext{
${ }^{1}$ mostly located in close proximity or above the front (resp. rear) axle depending on vehicle models - or both axles in case of a four-wheel driven vehicle.
} 




Figure 4: Global maximum pass-by sound pressure level in $\mathrm{dB}(\mathrm{A})$ at constant speed for different EVs on a DAC 0/10 road surface ( -$)$ and on a SMA 0/14 road surface $(-)$ - Propulsion noise component of CNOSSOS-EU in reference conditions $(-\cdot-)$.

component separation approach through parameter degrees of freedom becomes ineffective [9]. Moreover, electric motor noise is characterized by emerging tones linked to orders, shifting from one octave band to the other depending on vehicle speed, with significant differences between EV models [15]. In the present situation where knowledge on outside electric propulsion noise is still incomplete, it would be a mistake to propose a definite speed-dependent mathematical expression describing the propulsion noise contribution in each octave. Although the global propulsion noise radiated involves low levels relatively to rolling noise, its relative contribution can remain significant in some frequency bands. Thus, until a more adequate statement is available, the present approach is proposed:

- the current model for category 1 is used, as expressed in equations (1) and (3),

- a constant correction coefficient $\Delta L_{W P, E V, i}$ is introduced on the propulsion noise in each octave $i$ for EVs,

- the rolling noise component will be discussed in section 3.2

This proposal implies that the model of EV propulsion noise level linearly increases in each octave with the same slope than ICE vehicles, which has no technical basis at this time but offers a simple and factually acceptable solution. Indeed, electric propulsion noise occurs to affect total noise in some octave bands and at very low speeds only. Thus, although not strictly correct, the exact trend with speed actually has an insignificant effect on the total noise at higher speeds. If the rolling noise is significantly reduced in future, then this statement should certainly be reconsidered. Since the dataset available for the analysis mainly refers to vehicle speeds larger than $20 \mathrm{~km} / \mathrm{h}$, extrapolation is not accepted here and the following developments are valid at speeds over $20 \mathrm{~km} / \mathrm{h}$.

Consequently, within the reference conditions defined in CNOSSOS-EU, the EV propulsion noise is given by:

$$
L_{W P, E V, i}(v)=A_{P, i}+B_{P, i}\left(\frac{v-v_{r e f}}{v_{r e f}}\right)+\Delta L_{W P, E V, i}
$$

where

- $A_{P, i}$ and $B_{P, i}$ are the official CNOSSOS-EU coefficients expressed in the octave band $i$ for vehicle category 1 , and for the reference speed $v_{\text {ref }}=70 \mathrm{~km} / \mathrm{h}[11]$.

- $\Delta L_{W P, E V, i}$ is the correction coefficient to be introduced for EVs in the octave band $i$.

Practically, these correction coefficients are determined by comparing the sample of EVs to a sample of ICE vehicles on the same test site, other things being equal. The test site with a DAC 0/10 road surface was selected for this, since it provides the wider speed range and larger vehicle sets. The principle of the approach used to determine the correction coefficients involves the following steps in each octave band: 

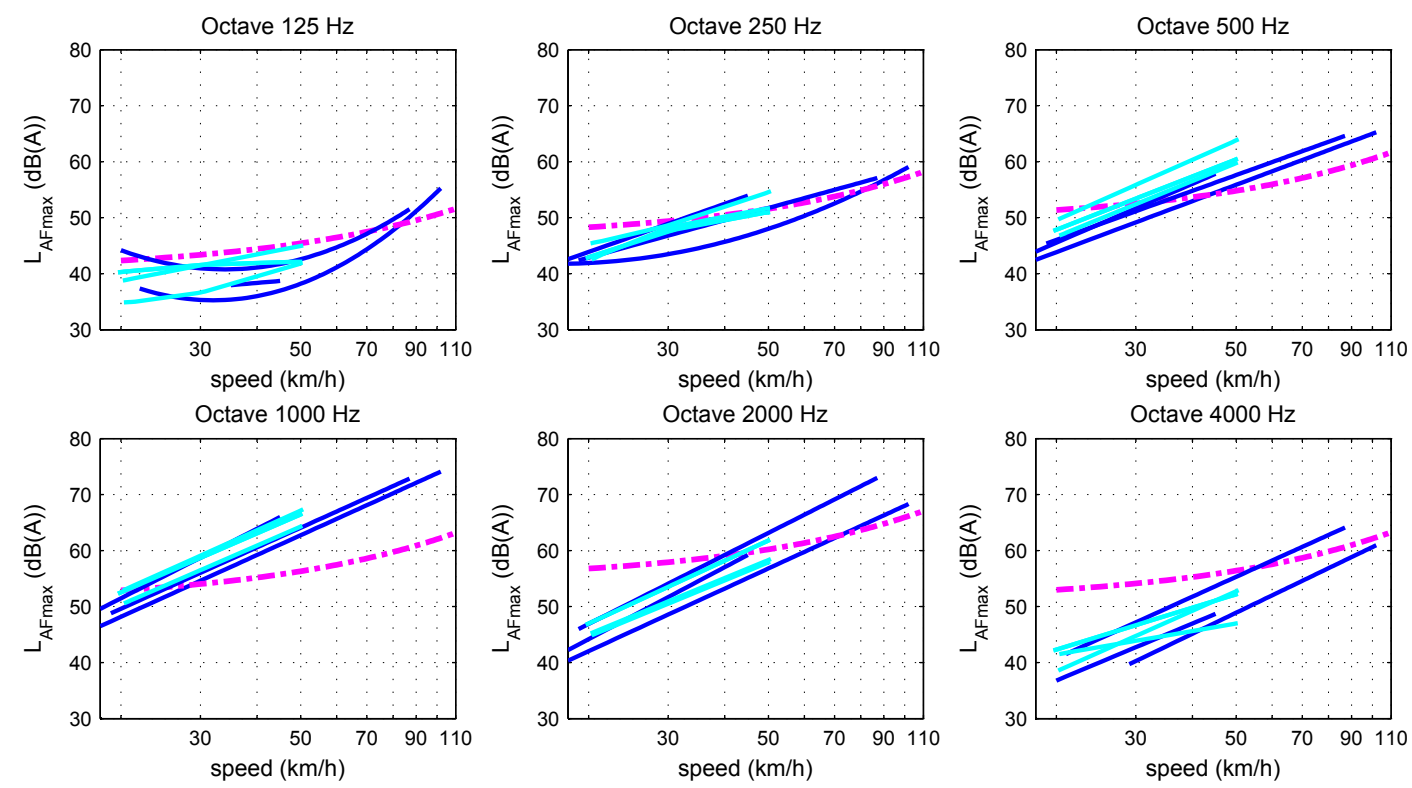

Figure 5: Maximum pass-by sound pressure level in $\mathrm{dB}(\mathrm{A})$ at constant speed for different EVs in octave bands on a DAC $0 / 10$ road surface (-) and on a SMA 0/14 road surface (-) - Propulsion noise component of CNOSSOS-EU in reference conditions (- - -).

1. From measurements of ICE vehicles on the DAC 0/10 test road, an ICE propulsion noise component $L_{W P, I C E, i}(v)$ similar to equation $(1)$ is determined.

2. From the measurement of EVs on the same test site and according to equation (7), the correction coefficient is given by the difference:

\subsubsection{Determination of the propulsion noise component of the ICE cars}

Pass-by noise levels measured at $7.5 \mathrm{~m}$ with $11 \mathrm{ICE}$ cars have been used. This set of cars ranges from small to large passenger cars, including a SUV2 Seven cars have a diesel engine and four have a gasoline engine. Since the propulsion noise level of this car sample slightly differs from CNOSSOS-EU, the model is first adjusted to better fit the data, as described below.

In a first step, each ICE car is considered individually. For each one (numbered with $n$ from 1 to 11 ), the noise levels were measured over a wide range of vehicle speeds and engine speeds. Then, the total noise level in octave $i$ is decomposed in a powertrain noise level component $\left(L_{W, \text { powertrain, }, i}\right.$ function of the engine speed $\left.r p m\right)$ and a rolling noise level component $\left(L_{W, \text { rolling,n,i}}\right.$ function of the vehicle speed $\left.v\right)$ [16]:

$$
\begin{aligned}
& L_{W, n, i}(\text { rpm }, v)=L_{W, \text { powertrain }, n, i}(r p m) \oplus L_{W, \text { rolling }, n, i}(v) \\
& L_{W, \text { powertrain }, n, i}(r p m)=a_{p, n, i}+b_{p, n, i} \log \left(\frac{r p m}{r p m_{\text {ref }}}\right) \\
& L_{W, \text { rolling }, n, i}(v)=a_{r, n, i}+b_{r, n, i} \log \left(\frac{v}{v_{r e f}}\right)
\end{aligned}
$$

The coefficients $a_{p, n, i}, b_{p, n, i}, a_{r, n, i}$ and $b_{r, n, i}$ are determined by a classic optimization procedure involving the measures and the previous model. Then, the powertrain noise level in octave $i$ representative of car $n$ in usual driving conditions is inferred for a specific strategy of gear shifting (which uniquely relates the engine rpm to vehicle speed), based on the car engine power [9]. Thus, the powertrain noise - and the total noise recomposed accordingly from both noise

${ }^{2}$ Sport Utility Vehicle 
components - exhibits a series of switchbacks as a function of the sole vehicle speed, due to the gear shifts. Finally, these results for the 11 cars are used to derive an average model of the car set consistent with CNOSSOS model, as described below.

In each octave, the mean total noise $L_{W, I C E, i}(v)$ (respectively the mean $L_{W r o l l, I C E, i}(v)$ of the rolling noise components) is averaged from the 11 ICE cars. These represent the average ICE car. Finally, the best fit for the propulsion noise model of the average ICE car consistent with CNOSSOS-EU is calculated by using:

$$
L_{W, I C E, i}(v)=L_{W P, I C E, i}(v) \oplus L_{W r o l l, I C E, i}(v)
$$

with:

$$
L_{W P, I C E, i}(v)=A_{P, I C E, i}+B_{P, i}\left(\frac{v-v_{r e f}}{v_{r e f}}\right)
$$

where $A_{P, I C E, i}(v)$ is the only unknown parameter, determined in each octave band through the optimisation process. $B_{P, i}$ is given in CNOSSOS-EU (Category 1). Thus, $L_{W P, I C E, i}(v)$ has the same trend as the CNOSSOS-EU propulsion component; only the intercept is modified. It turns out that the propulsion noise component has always a significant contribution in the total noise, at least at low speed. Its lowest contribution occurs in octave $1000 \mathrm{~Hz}$, where it is evaluated only $3.5 \mathrm{~dB}(\mathrm{~A})$ below rolling noise. Hence the optimization result for parameter $A_{P, I C E, i}$ is considered as accurate enough and meaningful in all octave bands.

\subsubsection{Determination of the propulsion noise component of EVs}

Similarly, the average of the EV noise levels is calculated in each octave. The corresponding propulsion noise component is determined by fitting a 2-component model to the average data:

$$
L_{W, E V, i}(v)=L_{W P, E V, i}(v) \oplus L_{W R, E V, i}(v)
$$

where

$$
\begin{aligned}
& L_{W P, E V, i}(v)=A_{P, E V, i}+B_{P, i}\left(\frac{v-v_{r e f}}{v_{r e f}}\right) \\
& L_{W R, E V, i}(v)=A_{R, E V, i}+B_{R, i} \log \left(\frac{v}{v_{r e f}}\right)
\end{aligned}
$$

with two unknowns $A_{P, E V, i}$ and $A_{R, E V, i} . B_{P, i}$ (resp. $B_{R, i}$ ) is the slope of the propulsion (resp. rolling) noise component given in CNOSSOS-EU.

The correction coefficient is given by

$$
\Delta L_{W P, E V, i}=L_{W P, E V, i}(v)-L_{W P, I C E, i}(v)=A_{P, E V, i}-A_{P, I C E, i}
$$

which is a constant specific to each octave. In the octave bands where rolling noise is widely dominating, the estimated propulsion noise level of the average EV is very small. In these cases and for displaying consistent values while assuring an insignificant contribution of the component, the correction coefficient has been arbitrarily limited to $15 \mathrm{~dB}(\mathrm{~A})$.

Table 1: Correction coefficients $\Delta L_{W P, E V, i}$ for the propulsion noise component, to be applied to CNOSSOS-EU propulsion noise component for the light vehicles in all-electric mode.

\begin{tabular}{|c|cccccc|}
\hline Octave & $125 \mathrm{~Hz}$ & $250 \mathrm{~Hz}$ & $500 \mathrm{~Hz}$ & $1000 \mathrm{~Hz}$ & $2000 \mathrm{~Hz}$ & $4000 \mathrm{~Hz}$ \\
\hline Correction coeff. & $-1.7 \mathrm{~dB}$ & $-4.2 \mathrm{~dB}$ & $-15 \mathrm{~dB}$ & $-15 \mathrm{~dB}$ & $-15 \mathrm{~dB}$ & $-13.8 \mathrm{~dB}$ \\
\hline
\end{tabular}

\subsubsection{EV propulsion noise model}

The model of the electric propulsion noise component, in the reference conditions [11], is expressed by:

$$
L_{W P, E V, i}(v)=A_{P, i}+B_{P, i}\left(\frac{v-v_{r e f}}{v_{r e f}}\right)+\Delta L_{W P, E V, i}
$$

where 
- $A_{P, i}$ and $B_{P, i}$ are the official CNOSSOS-EU coefficients expressed in the octave band $i$ for ICE vehicle category 1 and the reference speed $v_{\text {ref }}=70 \mathrm{~km} / \mathrm{h}$.

- $\Delta L_{W P, E V, i}$ is the correction coefficient to be introduced for EVs in the octave band $i$. The values of $\Delta L_{W P, E V, i}$ are given in Table 1 and have been arbitrarily limited to $-15 \mathrm{~dB}(\mathrm{~A})$.

For completeness, it would be appropriate to verify the adequacy of the other correction terms provided in CNOSSOS-EU, in particular regarding the effect of road gradients and acceleration/deceleration for EVs. This has not been addressed in this study.

\subsection{Rolling noise emission of electric vehicles}

Electric vehicles are mostly equipped with tyres offering a low rolling resistance in order to favour low energy consumption and consequently a higher driving range, which is an essential argument for the expansion of this vehicle technology. However, these do not form a majority part of the tyre models available in the EU market [17]. Some models have also been specifically developed for or selected by electric vehicle manufacturers. On the other end, CNOSSOS-EU mainly relies on data gathered in the early 2000s, with a vehicle fleet equipped with an older tyre generation than nowadays. This section focusses on rolling noise from tyres appropriate for electric vehicles and compares it to the CNOSSOS-EU rolling noise model in order to assess its representativeness for this vehicle category.

255 3.2.1. Assessment of the noise emission from a set of tyres

Experimental approach. Tyre-road noise produced by an electric vehicle fitted with various tyre types has been analysed by controlled pass-by measurements (CPB) at constant speed with motor running (cruise-by) [14]. The measurement set-up was as close as possible to common standards on vehicle noise [18, 6]. The physical parameter used is the maximum A-weighted sound pressure level $\left(L_{A F \max }\right)$ during the pass-by of a test vehicle at steady speed, recorded on a microphone located $7.5 \mathrm{~m}$ from the track centre and at a height of $1.2 \mathrm{~m}$ above ground, either in global levels or in octave bands. All sound pressure levels have been normalised to the reference air temperature $20^{\circ} \mathrm{C}$, using a correction of $0.08 \mathrm{~dB} /{ }^{\circ} \mathrm{C}$ as given in the CNOSSOS-EU model.

The test road, covered with asphalt concrete of $11 \mathrm{~mm}$ chipping size (AC11), was located between two fields with short vegetation. The standard specification allows a surface with significant absorption between the microphone and the road over a relative length not greater than 50\%. However, this condition was not fulfilled, the road surface accounting for $25 \%$ of the whole length. For the configuration involved, excess attenuations have been estimated using the Rasmussen model [19] and correction values have been applied to the measured values as described in Appendix 2. Thus, the corrected noise levels used in the analysis are reduced to a configuration offering the same uniform reflecting surface from the driving lane to the microphone position. The corrected global levels encompass the frequency range 110 to $5610 \mathrm{~Hz}$.

Four identical test tyres (dimension 205/55 R16) were fitted on a Renault Fluence Z.E. and the pass-by noise emission was measured at several constant speeds between $10 \mathrm{~km} / \mathrm{h}$ and $130 \mathrm{~km} / \mathrm{h}$. Eight different sets of tyres, listed as $\mathbf{A}$ to $\mathbf{H}$ in Table 2, have been tested. All tyre models were selected for their good rolling resistance performance (EU-label A or B amongst an actual A-G label range), since this represents a critical parameter for energy consumption and consequently the electric range of the vehicle. None of them is exclusively dedicated to electric vehicles, but tyre $\mathbf{B}$ is the normal equipment selected by the vehicle manufacturer for the Renault Fluence Z.E.

An additional tyre (tyre $\boldsymbol{I}$ in Table 2 has been tested. It has the particularity to have been specifically developped by the manufacturer for an electric vehicle (Renault ZOE). The additional tests carried out here with this tyre involve a different car, different tyre dimensions (195/55 R16), a different test site - but also with an AC11 road surface - and a lower maximum speed. This difference is outlined with italics in Table 2

After a careful examination of the noise levels at low speed with regard to background noise levels, a $3 \mathrm{~dB}$ criterion for the minimum difference between the test sound pressure level and the background noise level was used for validating the data, without correction on the levels.

The analysis focuses mainly on the relative tyre differences and the sound pressure level is analyzed in regard to speed.

${ }^{3}$ Coast-by conditions are unfeasible on electric vehicles with no gearbox since the clutch cannot be disengaged. Releasing the accelerator pedal immediately calls for the energy recovery system, involving a higher deceleration rate and a new noise source contribution. 
Table 2: Set of tyres selected for the measurements. The EU label is in the format \{Rolling Resistance / Wet Grip / Noise Emission\} (see details in Section 3.2.2.

\begin{tabular}{|c|c|c|}
\hline Tag & Dimensions & EU Label \\
\hline A & $205 / 55 \mathrm{R} 1691 \mathrm{H}$ & $\mathrm{B} / \mathrm{A} / 68$ \\
B & $205 / 55 \mathrm{R} 1691 \mathrm{H}$ & $\mathrm{C} / \mathrm{C} / 68$ \\
C & $205 / 55 \mathrm{R} 1691 \mathrm{~V}$ & $\mathrm{~B} / \mathrm{B} / 67$ \\
D & $205 / 55 \mathrm{R} 1691 \mathrm{H}$ & $\mathrm{B} / \mathrm{B} / 70$ \\
E & $205 / 55 \mathrm{R} 1691 \mathrm{~V}$ & $\mathrm{~A} / \mathrm{C} / 70$ \\
F & $205 / 55 \mathrm{R} 1691 \mathrm{H}$ & $\mathrm{B} / \mathrm{B} / 69$ \\
$\mathbf{G}$ & $205 / 55 \mathrm{R} 1691 \mathrm{~W}$ & $\mathrm{~B} / \mathrm{A} / 70$ \\
$\mathbf{H}$ & $205 / 55 \mathrm{R} 1691 \mathrm{H}$ & $\mathrm{B} / \mathrm{B} / 70$ \\
$\boldsymbol{I}$ & $195 / 55 R 1691 Q$ & $\mathrm{~A} / \mathrm{A} / 70$ \\
\hline
\end{tabular}

Global level and octave band analysis. The maximum global noise levels measured at pass-by and constant speed exhibit a quite linear behaviour with $\log ($ speed) (Figure 6). The regression coefficients are given in Table 3 The difference between the quietest and the noisiest tyre on the Fluence Z.E., estimated from the regression lines, varies between 2.1 and $3.6 \mathrm{~dB}(\mathrm{~A})$ over the speed range. All things being equal, tyres $\mathbf{A}$ and $\mathbf{B}$ are the noisiest whereas the quietest tyres are $\mathbf{D}$ at low speed and $\mathbf{H}$ at high speed. The tyre $\mathbf{I}$, measured in somewhat different conditions as reported before, meets with the less noisy ones. Tyre ranking relative to noise does not change much throughout the speed range.

The levels in octave bands are taken at the time of the maximum of the overall level. Per frequency band, the sound levels do not systematically increase linearly with $\log ($ speed $)$, especially at low speed where propulsion noise may contribute in cruise-by conditions (cf. section 3.1). However, rolling noise is predominant at least at high speed. The octave noise level difference among tyres at a given speed is often wider than with global levels, and the tyre ranking may dramatically change from one octave band to another (Figure 7). For making figure reading easier only, either linear or quadratic regression curves have been added to Figure 7 for each tyre case.

Table 3: Regression equations of the maximum global noise level for the 9 tyres at cruise-by $\left(v_{\text {ref }}=70 \mathrm{~km} / \mathrm{h}\right)$.

\begin{tabular}{|c|c|c|}
\hline Tyre & Regression equation & $\begin{array}{c}\text { Coefficient of } \\
\text { determination }\left(R^{2}\right)\end{array}$ \\
\hline $\mathbf{A}$ & $L_{A F \max }=33.5 \log \left(\frac{v}{v_{\text {ref }}}\right)+74.3$ & 0.994 \\
$\mathbf{B}$ & $L_{A F \max }=34.7 \log \left(\frac{v}{v_{\text {ref }}}\right)+74.7$ & 0.992 \\
$\mathbf{C}$ & $L_{A F \max }=36.3 \log \left(\frac{v}{v_{\text {ref }}}\right)+73.0$ & 0.997 \\
$\mathbf{D}$ & $L_{A F \max }=36.3 \log \left(\frac{v}{v_{\text {ref }}}\right)+72.7$ & 0.995 \\
$\mathbf{E}$ & $L_{A F \max }=34.0 \log \left(\frac{v}{v_{\text {ref }}}\right)+73.4$ & 0.987 \\
$\mathbf{F}$ & $L_{A F \max }=34.9 \log \left(\frac{v}{v_{\text {ref }}}\right)+73.3$ & 0.993 \\
$\mathbf{G}$ & $L_{A F \max }=34.2 \log \left(\frac{v}{v_{\text {ref }}}\right)+73.6$ & 0.999 \\
$\mathbf{H}$ & $L_{A F \max }=34.4 \log \left(\frac{v}{v_{\text {ref }}}\right)+72.5$ & 0.998 \\
$\boldsymbol{I}$ & $L_{\text {AFmax }}=37.4 \log \left(\frac{v}{v_{\text {ref }}}\right)+72.7$ & 0.989 \\
\hline
\end{tabular}

\subsubsection{EU exterior noise label and low-noise tyres}

The EU labels, used for tyre marking, intend to inform the consumer on the tyre performance relating to fuel consumption, safety on wet road and environmental noise emission, the last one being of particular concern here (Figure 8). The two former are expressed respectively through the rolling resistance and the wet grip, each being 


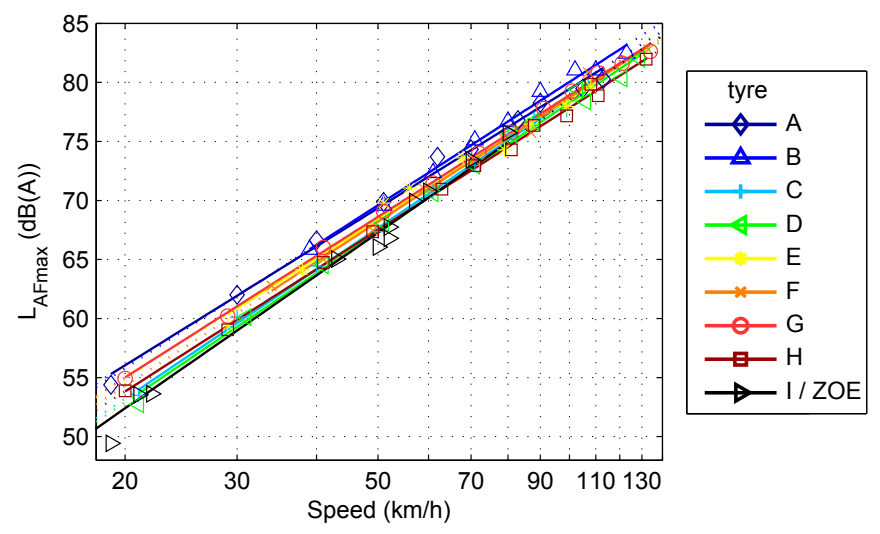

Figure 6: Global maximum pass-by sound pressure level in $\mathrm{dB}(\mathrm{A})$ at constant speed for different tyres - the symbols mark the individual measurements used for the regression, the dotted lines are extrapolation areas.

indicated by letters grading from A (highest performance) to $\mathrm{G}$ (least performing tyres ${ }_{4}^{\sqrt{4}}$ However, the exterior noise label expresses two concepts: an absolute rolling noise level and a positioning relative to the type approval noise limit, which varies with tyre class and width. A 3-black wave pictogram stands for a tyre with a noise level larger than the noise limit value, a 2-black wave pictogram indicates a noise level situated 0 to $3 \mathrm{~dB}$ under the noise limit while a 1black wave pictogram is used for a noise value at least $3 \mathrm{~dB}$ below the noise limit. The labels are determined according to procedures described in the UN (ECE) regulation No. 117 [6]. The exterior noise measurement conditions and method for light vehicle tyres include the following specifications:

- The road surface shall be in accordance with ISO 10844:2011. The test site shall offer semi-free field conditions.

- The vehicle is fitted with four identical tyres.

- The A-weighted maximum sound pressure level (time weighting Fast) is recorded at vehicle coast-by (engine off, gear at neutral) on microphones located $7.5 \mathrm{~m}$ from the track centre line and $1.2 \mathrm{~m}$ above the ground.

- Temperature corrections are applied, according to the test surface temperature, to normalize to the reference $20^{\circ} \mathrm{C}$.

A minimum of eight measurements on each vehicle side is required, with test speeds ranging from 70 to $90 \mathrm{~km} / \mathrm{h}$. A regression equation relating the maximum noise level to $\log ($ speed $)$ is determined, and the noise level at the reference speed $80 \mathrm{~km} / \mathrm{h}$ is inferred. The final result is reduced by $1 \mathrm{~dB}(\mathrm{~A})$ to take account of measuring inaccuracies and rounded down to the nearest whole value.

In this subsection the EU noise labels of the nine tyres tested and the resulting tyre ranking are compared with the noise levels measured with the tyres fitted to the Fluence Z.E. and the ZOE. Consequences for a concept of low noise tyres related to EU labels are inferred.

Comparison of the measurement results with the EU noise labels. The EU noise labels of the eight tyres fitted to the Fluence Z.E. and the tyre fitted to the ZOE, as listed in Table 2 , are compared with the corrected noise levels measured on the AC11 road surface, through a calculation at the reference speed $80 \mathrm{~km} / \mathrm{h}$ based on the regression lines displayed in Figure 6 As might be expected due to road texture differences, the actual noise levels on the AC11 surface are higher than the EU Noise Label. But the main observations here concern noise level scattering and tyre ranking. It turns out that the noise measurements at $80 \mathrm{~km} / \mathrm{h}$ have a reduced spread on AC11 against the EU labels. Furthermore, the EU noise label does not properly reflect the tyre ranking given by the noise measurement performed on the AC11 surface since no common trend can be noticed between noise labels and the actual noise levels (Figure 9p).

\footnotetext{
${ }^{4}$ The label D is never used (empty class) for a better separation between tyres with good and bad performance. The class G is empty for the wet grip only.
} 

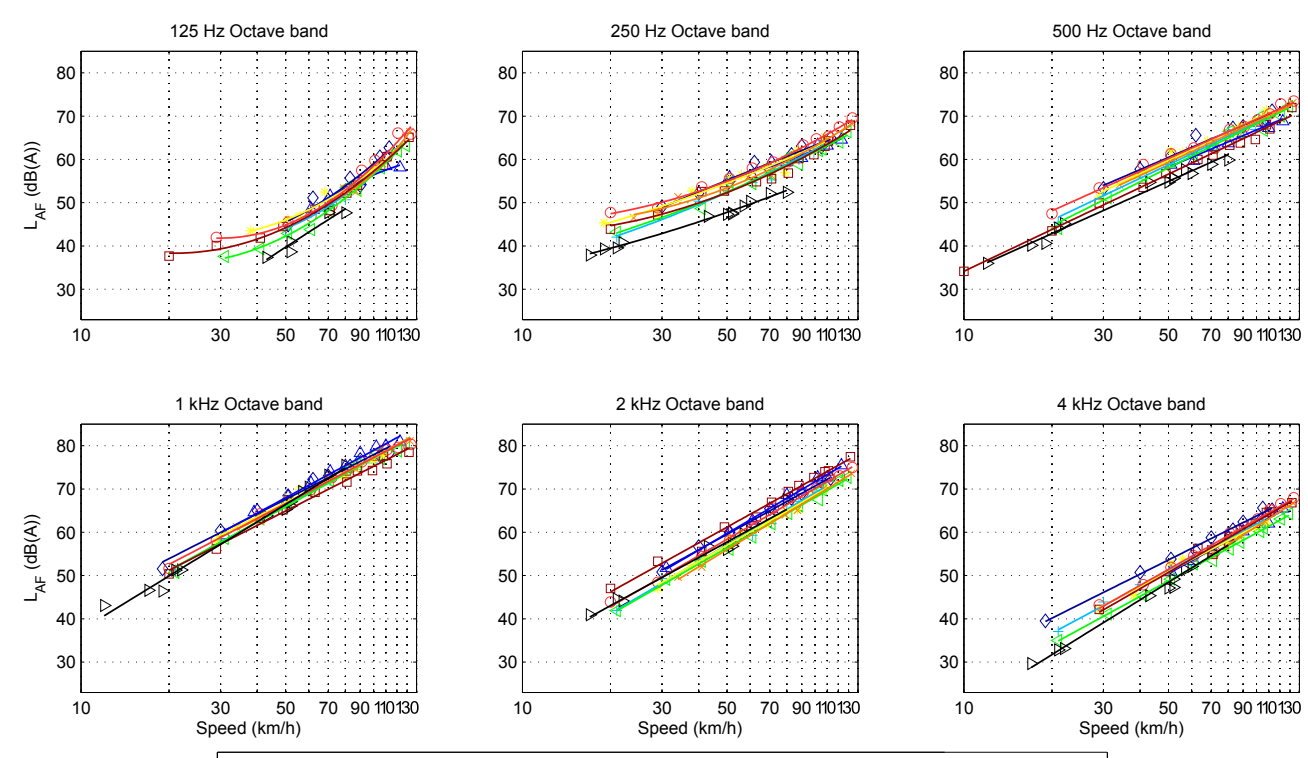

Figure 7: Maximum pass-by sound pressure level in $\mathrm{dB}(\mathrm{A})$ at constant speed for different tyres in octave bands - the symbols mark the individual measurements used for the regression.

Table 4: Impact of a tyre low-noise criterium on EV noise emission on AC11 - $[N L=E U$ tyre Noise Label $;$ LV $=$ EU Limit Value $=71$ $d B(A)]$

\begin{tabular}{|l|c|c|}
\hline Low-noise criterium & Tyres concerned & $\begin{array}{c}\text { Average noise level } \\
\text { at } 80 \text { km/h on AC11 }\end{array}$ \\
\hline$N L \leq L V-1$ & all & $75.4 \mathrm{~dB}(\mathrm{~A})$ \\
$N L \leq L V-2$ & $\mathrm{~A}, \mathrm{~B}, \mathrm{C}, \mathrm{F}$ & $75.8 \mathrm{~dB}(\mathrm{~A})$ \\
$N L \leq L V-3$ & $\mathrm{~A}, \mathrm{~B}, \mathrm{C}$ & $76.0 \mathrm{~dB}(\mathrm{~A})$ \\
\hline
\end{tabular}

Other recent studies pointed out similar findings, suggesting a lack of representativeness of the exterior noise EUlabels with actual noise levels on operational road surfaces [20, 21, 22]. The adequacy of the ISO surface for inferring tyre ranking on actual roads is questioned and has implications on the concept of low-noise tyres, as presented below.

Low-noise tyres. The concept of low-noise tyres has not yet been clearly defined, as underlined in [23]. It can be stated as referring to tyres granted with a noise label either $1 \mathrm{~dB}$ or $2 \mathrm{~dB}$ under the type approval limit value, or even $3 \mathrm{~dB}$ lower than the limit value which corresponds to a noise label rating with a 1-wave pictogram. The impact of one or the other definition of a low-noise tyre within the tyre set previously measured is analysed.

All the nine tyres investigated (Fluence and ZOE) belong to the same tyre subclass C1b featured with a nominal section width of 185 to $215 \mathrm{~mm}$ and a type approval limit value of $71 \mathrm{~dB}(\mathrm{~A})$ [6]. They all comply with this rolling noise limit value. Several low-noise criteria, based on the EU tyre noise label compared to the EU limit value, have been considered. In each case, the tyres satisfying the condition have been selected and the average EV noise level with these tyres at $80 \mathrm{~km} / \mathrm{h}$ on the AC11 road surface has been computed. The selected tyres turn out to be equally among the noisiest and the quietest out of the tyre set (Table 4). The lack of connection between the noise labels and the actual noise values measured during the vehicle pass-by tests would paradoxically lead to a slight (if not insignificant) worsening of the emitted noise if choosing more stringent tyre noise criteria based on the standard tyre labels.

Specific tyres fitted to electric vehicles. Within the tyre collection used for the measurements, two tyres may be more common with regard to electric vehicles: 


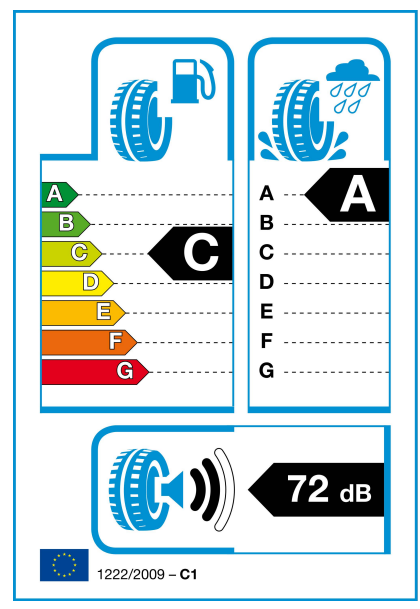

Figure 8: Example of an EU tyre label [from European Union].

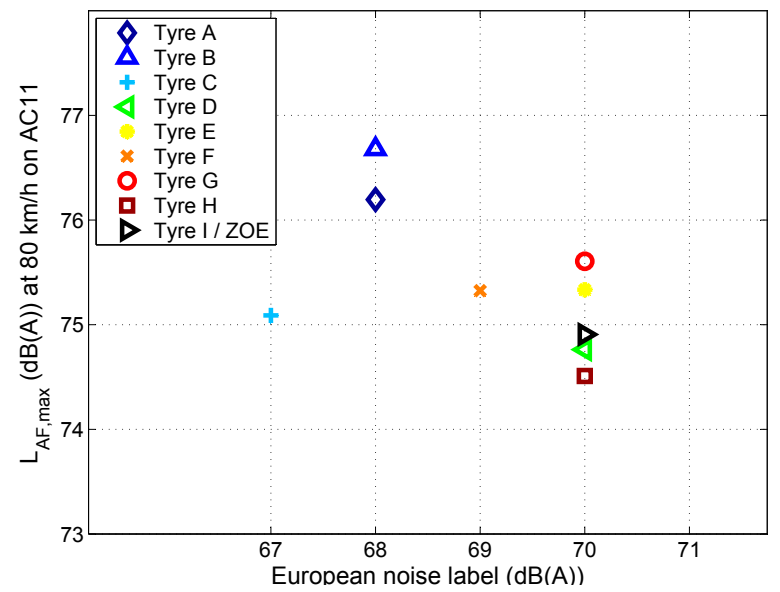

Figure 9: Comparison of the global noise levels measured on AC11 at $80 \mathrm{~km} / \mathrm{h}$ with the exterior noise labels, for the nine tyres of the tyre set. 
- tyre $\mathbf{B}$ which, though also available on the market for any vehicle, has been selected by the car manufacturer to exclusively fit the Fluence Z.E.,

- tyre $I$ which has been specifically designed for the ZOE.

When comparing the results specific to these two tyres with the overall noise range of the nine tyre measurements, it turns out that one of them belongs to the loudest tyres whereas the other is among the quietest tyres of the collection over the measurement speed range [17]. Thus, it can be inferred that, when rolling noise is the dominant source, a fleet of electric vehicles fitted with such tyres would not lead to a different global noise level than with common tyres. It may be recalled that these two tyres have been measured with different vehicles on different test sites with similar types of road surface: the result discrepancies cannot be definitely attributed to the sole tyre contribution and road texture differences might be suspected as well.

These findings are consistent with a behaviour which has also been pointed out by Ejsmont et al. [24] or Berge at al. [25] and in agreement with their point of view that "tires specially designed for Low Emission Vehicles are not particularly quiet. At best they emit tire/road noise of 'average' level".

\subsubsection{Rolling noise of EVs and CNOSSOS-EU}

This section investigates the relevance of corrections for the rolling noise component in CNOSSOS-EU. It relies on the latter measurements performed with eight different tyres and the Fluence Z.E on an AC11 surface, and on the former measurements carried out in section 2.1 with five light vehicles running in electric mode on a DAC 0/10 road surface. The measurements are compared with the rolling noise model already available from CNOSSOS-EU. A course is proposed accordingly for EVs rolling noise.

Investigations with the Fluence Z.E. The support of the experimental point cloud obtained from the eight tyres is considered here, as a sample of the extent of tyre diversity. The set of measured noise values is represented by a red surface (see Figures 10 and 11) including all noise levels measured at all speeds and for the eight tyres. For comparison, a prediction model derived from CNOSSOS-EU is computed. The propulsion noise component is the model specified in section 3.1 for predicting the propulsion noise from electric vehicles. The rolling noise component is those given by the CNOSSOS-EU method for conventional ICE vehicles. Since the measurement road surface is consistent with the CNOSSOS-EU reference conditions, no road correction term is added.

Investigation with 5 electric vehicles. The measurements involved five light vehicles of different sizes running in electric mode, involving various tyre sizes and makes/models. The test site had a DAC 0/10 road surface. The set of noise values measured at $7.5 \mathrm{~m}$ is represented by a green surface (see Figures 10 and 11 ) including all the regression curves describing the noise emission of the five vehicles in electric mode. A prediction model derived from CNOSSOS-EU is determined, where the propulsion noise component is the model specified in section 3.1 for predicting the propulsion noise from electric vehicles. The rolling noise component derives from the CNOSSOS-EU method for conventional vehicles, but a correction term has been included to take account of the actual road surface which differs from the CNOSSOS reference conditions. Details on this correction term are given in the appendix.

Discussion. The measurement results and the associated prediction models are given in global levels and in octave bands in Figures 10 and 11 . Only the rolling noise and the total noise of the model are plotted. Since CNOSSOS-EU is 385 an average model intended to represent an average vehicle on an average road surface whereas the sample dispersion may be significant, we will consider the model as satisfactory if the total noise is not disjoint from the corresponding coloured surface over most of the speed range.

The model (solid red line) overestimates only slightly the collection of global values measured on the AC11 test site (red patch). It is also satisfactory in the octaves $500 \mathrm{~Hz}, 1000 \mathrm{~Hz}$ and $4000 \mathrm{~Hz}$. However, the rolling noise component seems underestimated by $2-3 \mathrm{~dB}(\mathrm{~A})$ in the octaves $125 \mathrm{~Hz}$ and $250 \mathrm{~Hz}$, particularly noticeable at high speed, and is clearly overestimated by at least $3 \mathrm{~dB}(\mathrm{~A})$ in the octave $2000 \mathrm{~Hz}$ with a significant contribution to global levels.

The corrected model (solid green line) fits satisfactorily to the collection of global values measured on DAC 0/10 (green patch). Except for the octave $125 \mathrm{~Hz}$ where the results at high speed might require a slightly higher rolling noise contribution, the model is quite satisfactory in all the other octaves, particularly at high speed where the rolling noise contribution is dominating. 


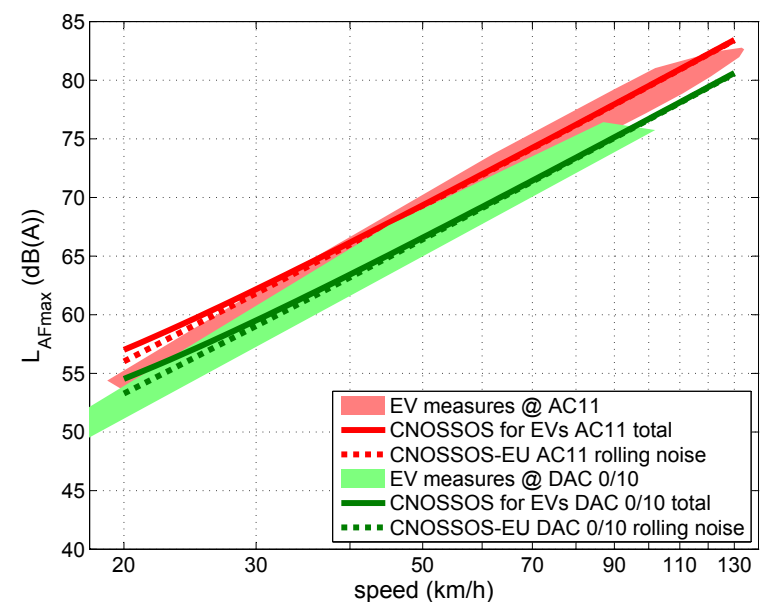

Figure 10: Global noise levels at $7.5 \mathrm{~m}$ measured with the 8 tyres fitted to the Fluence ZE on AC11 (red surface) and the 5 vehicles in electric modes on DAC 0/10 (green surface) with the respective prediction models - dashed line: rolling noise model - continuous line: total noise model

Inference for the rolling noise of EVs in CNOSSOS-EU. Taking account of the following findings on tyres and electric vehicles:

- The selection of tyres for electric vehicles by car and tyre manufacturers is firstly driven by energy efficiency requirements, relying on the rolling resistance performance of the tyre. Consideration of rolling noise is somewhat of secondary importance.

- No evidence of a trend between the rolling resistance performance and the rolling noise measured on actual road surfaces could be found [21, 17].

- The few tyres selected by car manufacturers to be fitted on their electric vehicles and tested to date do not acoustically behave differently from conventional tyres.

- Any tyre selection relying on a low-noise requirement based on EU noise labels would have no obvious effect on the rolling noise measured on actual road surfaces.

as well as the following findings based on the joint observation at high speeds of the measurement results and of the CNOSSOS-EU model corrected for the EV propulsion noise and without any modification of the rolling noise component (except for a correction linked with the road surface type):

- the model depicts noise levels measured on the DAC 0/10 quite well.

- the model depicts the noise levels measured on AC11 quite well in global levels, but with more or less significant discrepancies according to the octave bands.

it may be inferred, from the present perspective, that no correction is required for the rolling noise component given in CNOSSOS-EU.

\section{Complete model of the electric vehicle noise emission}

As a synthesis, we recommend the following extension of the standard CNOSSOS-EU model for representing the noise emission of electrically powered light vehicles in environmental noise prediction, available from the octave $125 \mathrm{~Hz}$ to the octave $4000 \mathrm{~Hz}$ :

- propulsion noise component: to apply equation (16) with the correction terms proposed in Table 1 . 

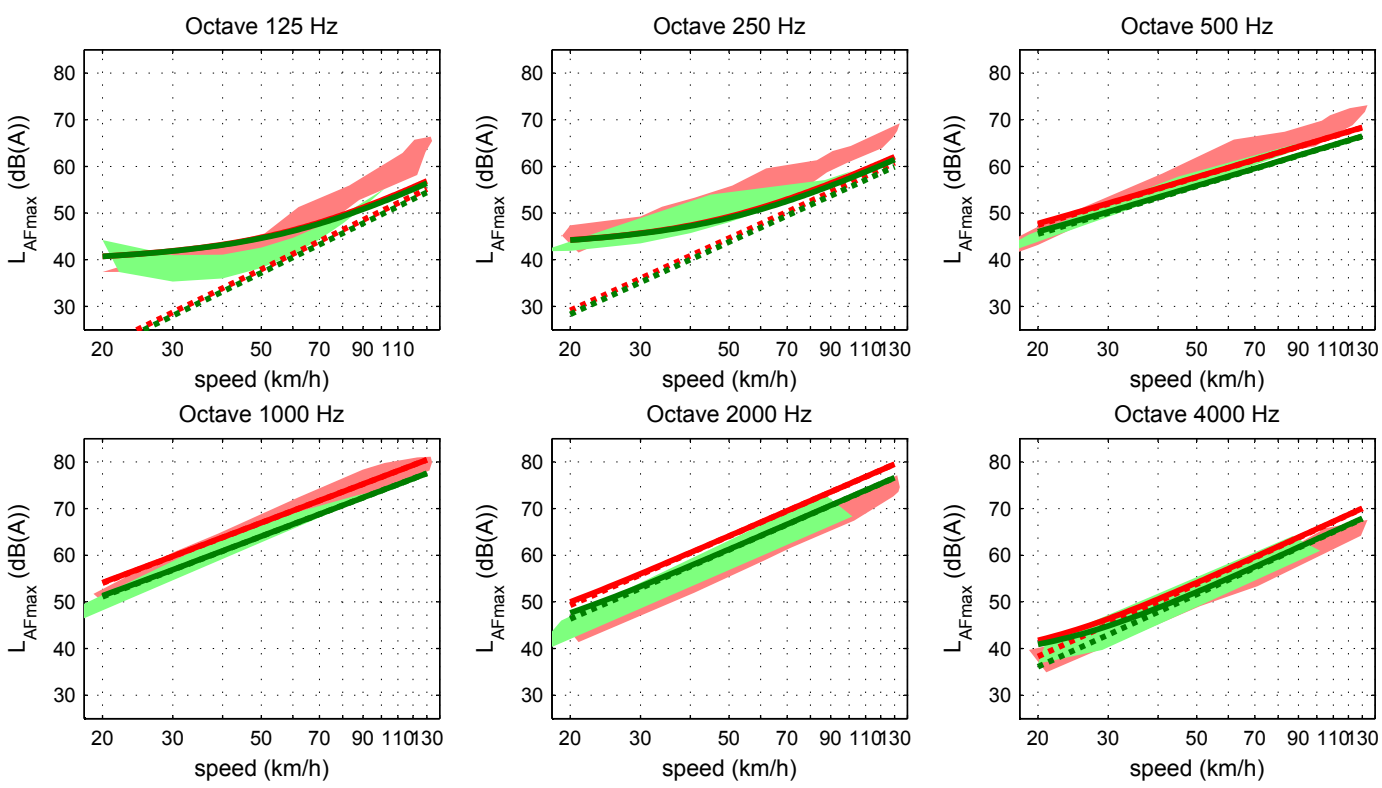

Figure 11: Noise levels in octave bands at 7.5 m measured with the 8 tyres on AC11 and the 5 vehicles in electric modes on DAC 0/10 - same legend as Figure 10

- rolling noise component: to use 'as it is' the rolling noise component given by CNOSSOS-EU for conventional vehicles.

Due to the limited amount of data available for assessing the proposed model, further investigation is required and any additional data are welcome to refine/validate the model.

\subsection{Comparison of the EV noise model to conventional vehicles in reference conditions}

The EV noise model in octave bands is illustrated in Figure 12 for the reference road surface and two other surfaces (SMA-NL8 and Thin Layer A, see section 2.3). Although our approach relies on data from EVs measured within the range [20-90 km/h], the EV model has been extrapolated up to $110 \mathrm{~km} / \mathrm{h}$, considering that propulsion noise is insignificant at these high speeds and the total noise is dominated by rolling noise, itself available in CNOSSOS-EU up to $130 \mathrm{~km} / \mathrm{h}$.

In the case of the reference road surface, when considering octave bands below $250 \mathrm{~Hz}$ the EV propulsion noise reduction in comparison to conventional vehicles in Figure 2 is moderate but factual; even by adding the rolling noise contribution, the overall noise decrease still remains appreciable over a wide speed range at these frequencies. At higher frequencies, the propulsion noise reduction is drastic, but the effect on the total noise may be low in the octave bands where rolling noise clearly dominates.

The overall global noise emitted by EVs exceeds only very slightly the sole rolling noise contribution in the reference conditions (Figure 13). Whereas the global EV propulsion noise reduction from conventional vehicles is large, the overall noise reduction remains more moderate, still reaching $5 \mathrm{~dB}(\mathrm{~A})$ at $20 \mathrm{~km} / \mathrm{h}$ but decreasing and becoming insignificant beyond 40-50 km/h (Table 5 ).

\subsection{Behaviour with other road surfaces}

With a dense road surface offering much quieter rolling noise conditions, the propulsion noise decrease is unchanged but the overall noise reduction may become more significant at low or even medium speeds. This is only weakly outlined through the road surface SMA-NL8 which differs very little from the reference one.

On the other hand, a porous road surface like Thin Layer A, since yielding a similar reduction on both the propulsion and the rolling noise, equally operates on the emission of conventional light vehicles and EVs: except in cases of 

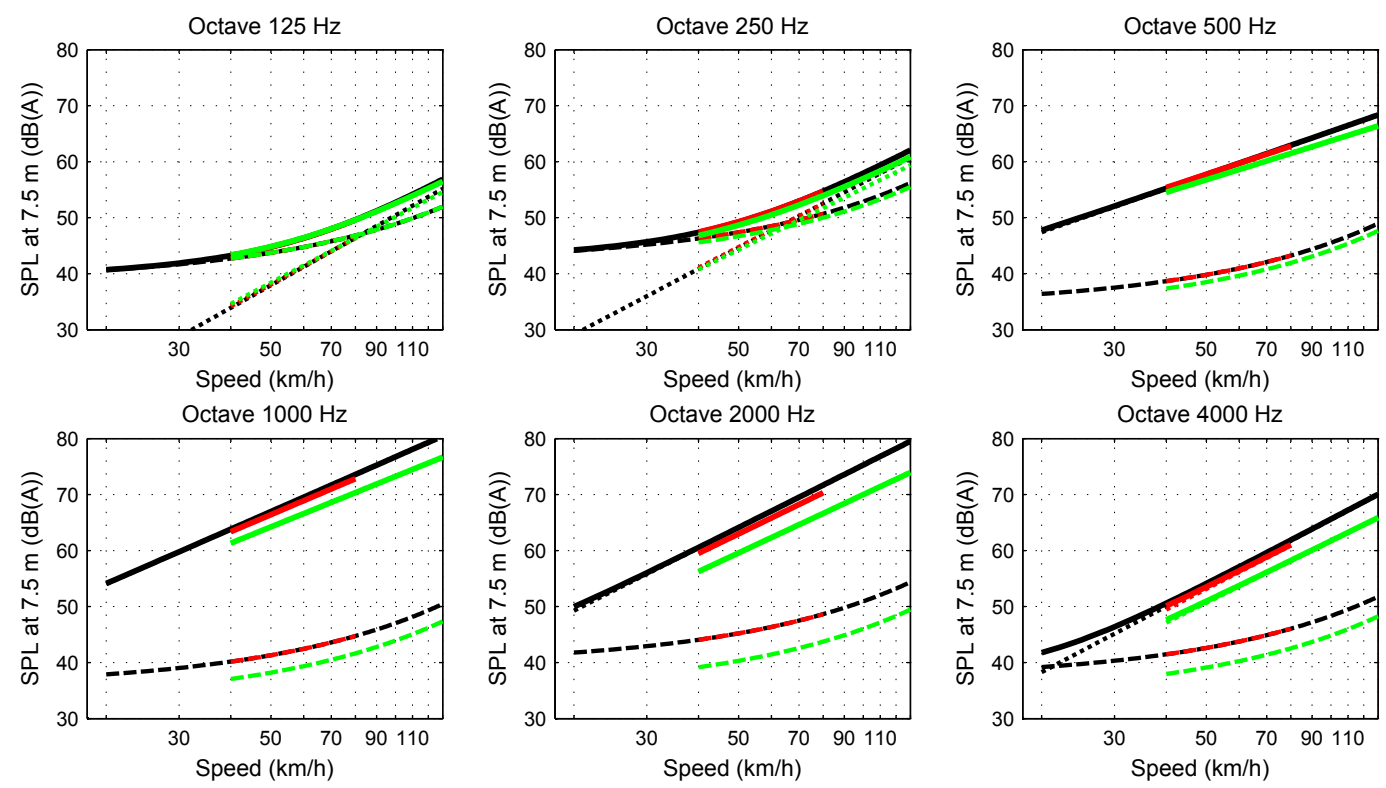

Figure 12: Sound Pressure Level in $\mathrm{dB}(\mathrm{A})$ in octave bands at $7.5 \mathrm{~m}$ from the track centre associated with the electric vehicle noise emission model, in the reference conditions (black), with the SMA-NL8 (red) and the Thin Layer A (green) road surfaces - Propulsion noise component (- -), rolling noise component $(\cdots)$, total noise $(-)$

strong spectral discrepancies, the global sound level difference between these car technologies is quite similar on the reference or a porous surface.

These vehicle noise level differences actually apply to individual vehicles, as heard for instance by residents or other users who are sensitive to single events on less busy roads. In case of a traffic stream, mixing conventional and electric driven cars (not to mention the presence of heavier vehicles), the noise benefit introduced by EVs is weakened and becomes minor or even imperceptible, depending on the fraction of electric cars and the type of road surface [26].

Table 5: Global noise level differences in $\mathrm{dB}(\mathrm{A})$ between the total noise of the electric vehicle model and the CNOSSOS-EU ICE vehicle model, respectively on the CNOSSOS-EU reference road surface, the SMA-NL8 and Thin Layer A road surfaces, for various pass-by speeds

\begin{tabular}{|c|ccc|}
\hline Speed & \multicolumn{3}{|c|}{ Road surface } \\
$\mathbf{k m} / \mathbf{h}$ & ref. & SMA-NL8 & Thin Layer A \\
\hline 20 & -5.0 & $\times$ & $\times$ \\
30 & -2.6 & $\times$ & $\times$ \\
40 & -1.6 & -1.7 & -1.4 \\
50 & -1.0 & -1.0 & -1.0 \\
70 & -0.6 & -0.7 & -0.6 \\
90 & -0.5 & $\times$ & -0.5 \\
110 & -0.4 & $\times$ & -0.4 \\
\hline
\end{tabular}




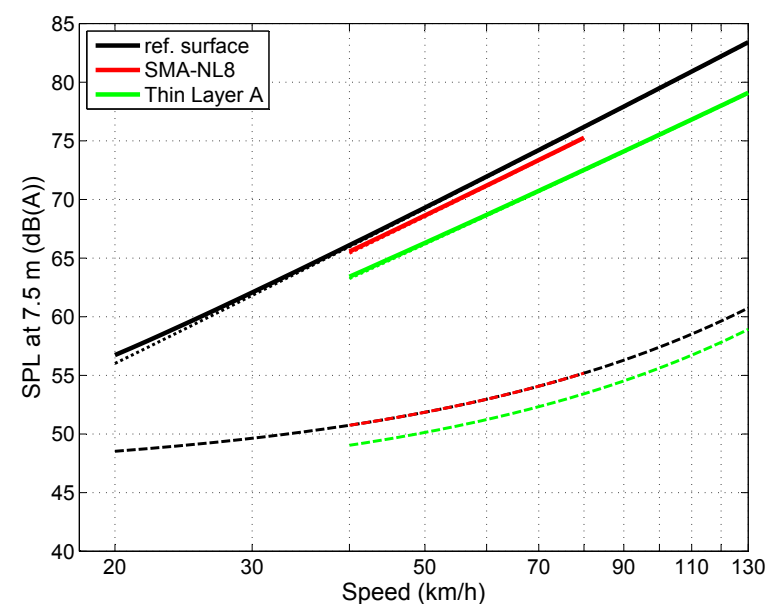

Figure 13: Global Sound Pressure Level in $\mathrm{dB}(\mathrm{A})$ at $7.5 \mathrm{~m}$ from the track centre associated with the electric vehicle noise emission model, in the reference conditions (black), with the SMA-NL8 (red) and the Thin Layer A (green) road surfaces - Propulsion noise component (- -), rolling noise component $(\cdots)$, total noise $(-)$

\section{Conclusion}

The CNOSSOS-EU method is recommended in Europe for environmental noise prediction. It includes data for modeling the noise emission of an average conventional vehicle through a propulsion noise component and a rolling noise component. On the basis of experimental data, the present study showed that this emission model is incorrect for electrically powered vehicles (including all-electric vehicles and hybrid vehicles in temporary all-electric mode) since it overestimates the noise levels in most octave bands at low speed, sometimes up to $50-60 \mathrm{~km} / \mathrm{h}$ due to an overvaluation of the propulsion noise contribution. Correction terms to be applied to the propulsion noise component have been proposed, when driving at a constant speed. It has also been shown that the use of tyres identified as ecological regarding energy consumption or more specifically targeted for electric vehicles has no significant effect on the rolling noise. Thus, the rolling noise component available in CNOSSOS-EU does not need any correction for electric vehicles. EU tyre labels on exterior noise and the concept of low-noise tyres have been investigated, putting forward the lack of an obvious relation with the noise emission on the common road surfaces tested in the study. Owing to the limited vehicle sample as well as transitional statements on propulsion noise behaviour, the new model for electric vehicles proposed in this paper for speeds over $20 \mathrm{~km} / \mathrm{h}$ should be considered as a first step towards the definition of this vehicle technology in CNOSSOS-EU.

In the reference road surface conditions, involving a virtual road surface consisting of an average of dense asphalt concrete $0 / 11$ and stone mastic asphalt $0 / 11$, the global noise level at roadside does not exceed much the sole rolling noise contribution, and the noise reduction by EVs at low speed is significant. This situation may concern urban driving situations as well as road sections with limited speed or traffic congestion on interurban or national networks. However, the approximation of the vehicle noise emission by the sole rolling noise component would turn out to be insufficient for the calculation of noise exposure at long distance, which is the main scope of the CNOSSOS-EU methods. Actually, at low speeds the contribution of propulsion noise to the total noise is significant in the lower frequency bands, where the sound happens to be less attenuated during the propagation over long distances.

The use of a quieter dense road surface can increase the noise reduction by EVs and extend the speed range of real effectiveness towards upper speeds. However, a porous road surface equally reduces propulsion and rolling noise components in CNOSSOS-EU whatever the vehicle and, unless particular frequency properties occur, keeps a global noise difference between both vehicle technologies similar to those in the reference conditions. In either case, it turns out that rolling noise and road surfaces play a crucial role in EV noise emission and form the main lever for further noise reduction by EVs. 


\section{Acknowledgement}

The project FOREVER has been funded under the CEDR Transnational Road Research Programme. The authors are grateful to the car manufacturers for providing vehicles.

\section{References}

485 [1] EEA, Noise in Europe 2014, Tech. Rep. 10/2014, European Environment Agency (2014).

[2] WHO, Burden of disease from environmental noise, no. 10/2014, WHO European Centre for Environment and Health, 2011.

[3] ANSES, Evaluation des impacts sanitaires extra-auditifs du bruit environnemental, Agence Nationale de Sécurité Sanitaire de l'Alimentation, de l'Environnement et du Travail (Anses), 2012.

[4] Directive 2002/49/EC of the European Parliament and of the Council of 25 June 2002 relating to the assessment and management of environmental noise, 2002

[5] Regulation (EU) No 540/2014 of the European Parliament and of the Council of 16 April 2014 on the sound level of motor vehicles and of replacement silencing systems, 2014.

[6] UN (ECE) Regulation No. 117 Rev. 3. Uniform provisions concerning the approval of tyres with regard to rolling sound emissions and/or to adhesion on wet surfaces and/or to rolling resistance, 2014

495 [7] IEA-HEV, Hybrid and Electric Vehicles - Annual report, International Energy Agency, 2015.

[8] F. Stenlund, Cityhush: Noise criteria for vehicles to enter Q-zones, Deliverable 322 2_110817 (2011)

[9] M. A. Pallas, J. Kennedy, I. Walker, R. Chatagnon, M. Bérengier, J. Lelong, Noise emission of electric and hybrid electric vehicles, Tech. Rep. FOREVER_WP2_D2-1_v4, CEDR (2015).

[10] G. Marbjerg, Noise from electric vehicles - a literature survey, COMPETT Program (2013).

500 [11] S. Kephalopoulos, M. Paviotti, F. Anfosso-Lédée, Common Noise Assessment Methods in Europe (CNOSSOS-EU), no. EUR 25379 EN, JRC, 2012.

[12] K. Kaliski, I. Old, L. Blomberg, Sound emissions from a plug-in electric vehicle, in: Proc. Internoise 2012, New York, USA, 2012.

[13] Commission Directive (EU) 2015/996 of the 19 May 2015 establishing common noise assessment methods according to Directive 2002/49/EC, 2015.

[14] AFNOR, Acoustique - caractérisation in situ des qualités acoustiques des revêtements de chaussées - mesurages acoustiques au passage procédure "véhicules maîtrisés", NFS 31119-2, (in French) (2002).

[15] D. Lennström, A. Nykänen, Interior sound of today’s electric cars: tonal content, levels and frequency distribution, SAE Technical Paper 2015-01-2367.

[16] J. Lelong, Vehicle noise emission: evaluation of tyre/road- and motor-noise contributions, in: Proc. Internoise 1999, Fort Lauderdale, Florida, USA, 1999.

[17] S. Gasparoni, M. Czuka, R. Wehr, M. Conter, M. A. Pallas, M. Bérengier, Impact of low-noise tyres on electric vehicle noise emission, Tech. Rep. FOREVER_WP3_D3-1_v7, CEDR (2015).

[18] ISO, Acoustics - Measurement of the influence of road surfaces on traffic noise - part 1: Statistical Pass-By method, DIN EN ISO 11819-1, NF EN ISO 11819-1 (2002).

[19] K. Rasmussen, A note on the calculation of sound propagation over impedance jumps and screens, Journal of Sound and Vibrations 84 (1982) 598-602.

[20] M. Muirhead, P. G. Abbott, M. Burdett, An examination of the monetised benefit of proposed changes to type approved noise limits for tyres, Tech. Rep. PPR394, TRL (2008).

[21] J. Kragh, J. Oddershede, NordTyre - Car tyre labelling and Nordic traffic noise, in: Proc. Internoise 2013, Innsbrück, Autriche, 2013.

520 [22] B. Swieczko-Zurek, J. Ejsmont, G. Ronowski, How efficient is noise labeling of tires?, in: Proc. ICSV 21, Beijing, China, 2014.

[23] T. Berge, NordTyre - Tyre/road noise testing on various road surfaces - State-of-the-Art, SINTEF, 2012.

[24] J. Ejsmont, B. Swieczko-Zurek, S. Taryma, Low noise tires for hybrid and electric vehicles, in: Proc. ICSV 21, Beijing, China, 2014.

[25] T. Berge, F. Haukland, P. Mioduszewski, R. Wozniak, Tyre/road noise of passenger car tyres, including tyres for electric vehicles - road measurements, in: Proc. Euronoise 2015, Maastricht, The Netherlands, 2015

525 [26] M. Muirhead, J. Kennedy, Environmental noise impacts of electric vehicles, Tech. Rep. FOREVER_WP4_D4-1_v2, CEDR (2015).

[27] M. Auerbach, M. Bérengier, DEUFRAKO - prediction and propagation of rolling noise: final results, in: Proc. Euronoise 2009, Edinburgh, Scotland, 2009.

[28] J.-F. Hamet, F. Besnard, S. Doisy, J. Lelong, E. Le Duc, New vehicle noise emission for French traffic noise prediction, Applied Acoustics 71 (2010) 861-869.

[29] M. Delany, E. Bazley, Acoustical properties of fibrous absorbent materials, Applied Acoustics 3 (1970) $105-116$.

\section{Appendix 1: Determination of correction terms for a DAC 0/10 road surface in the CNOSSOS-EU rolling noise component}

CNOSSOS-EU recommends applying a spectral correction factor on rolling noise for dense surfaces which differ from the reference conditions. This correction factor is given by:

$$
\Delta L_{W R, i}(v)=\alpha_{i}+\beta \log \left(v / v_{r e f}\right)
$$


where $\alpha_{i}$ is the correction in the octave band $i$ at the reference speed $v_{\text {ref }}$ and $\beta$ is the speed effect on rolling noise reduction (assumed independent of frequency). In the present case, which involves a common French road surface, the correction terms have been determined by using the data available in DEUFRABASE [27]. This database makes average third-octave rolling noise spectra of various road surfaces existing in France and Germany freely available. From the spectra given for an SMA 11 surface (considered here as being in accordance with CNOSSOS-EU reference road surface) and for a BBSG 0/10 surface (corresponding to the actual road surface type DAC 0/10), the correction terms $\alpha_{i}$ given in Table 6 have been determined. DEUFRABASE does not provide any information on the speed index of the road surfaces. By reference to the French method NMPB08, the two road surfaces belong to the same road surface category [28]. Then, the coefficient $\beta$ has been taken as $\beta=0$.

Table 6: Correction terms $\alpha_{i}$ applied to the CNOSSOS-EU rolling noise component for the DAC $0 / 10$ road surface

\begin{tabular}{|c|c|c|c|c|c|c|}
\hline Octave $i$ & $125 \mathrm{~Hz}$ & $250 \mathrm{~Hz}$ & $500 \mathrm{~Hz}$ & $1000 \mathrm{~Hz}$ & $2000 \mathrm{~Hz}$ & $4000 \mathrm{~Hz}$ \\
\hline$\alpha_{i}(\mathbf{d B}(\mathbf{A}))$ & -0.74 & -0.83 & -1.91 & -2.91 & -2.91 & -2.19 \\
\hline
\end{tabular}

\section{Appendix 2: Determination of the correction values due to impedance discontinuity between the road and its vicinity}

When determining the rolling noise level at the standard position (distance: $7.50 \mathrm{~m}$ and height: $1.20 \mathrm{~m}$ ), the national and ISO standards [14, 18] mention that the surface between the vehicle and the microphone has to be theoretically homogeneous. In actual situations, this hypothesis is rarely fulfilled and the microphone is often located in the road vicinity over an absorbing surface (for instance, grass or cultivated fields). In this particular case, the standards note that if the pavement covers at least $50 \%$ of the total distance, the error on the result is insignificant.

In the measurements carried out in section 3.2, the rate between road and neighbouring ground was close to $25 \%$. In that situation, the effect of the impedance discontinuity has to be taken into account. For the calculation, we used the Rasmussen's model [19] in which the impedances of the respective pavement and grounds are computed according to the Delany and Bazley impedance model [29]. In this empirical model the complex impedance is calculated from the airflow resistivity $\sigma$ of each surface. In the present case, the respective $\sigma$ values are $100000 \mathrm{kNsm}^{-4}$ for the pavement and between 400 and $1000 \mathrm{kNsm}^{-4}$ for the cultivated field. The average correction values adopted in this paper to assess the equivalent noise levels in $100 \%$ reflecting ground conditions are given in Table 7 .

Table 7: Average correction values applied to the measured noise levels in section 3.2

\begin{tabular}{|c|c|c|c|c|c|c|}
\hline Octave $i$ & $125 \mathrm{~Hz}$ & $250 \mathrm{~Hz}$ & $500 \mathrm{~Hz}$ & $1000 \mathrm{~Hz}$ & $2000 \mathrm{~Hz}$ & $4000 \mathrm{~Hz}$ \\
\hline $\mathbf{d B}(\mathbf{A})$ & 0.05 & 0.38 & 1.00 & 1.51 & 0.54 & -1.38 \\
\hline
\end{tabular}

